\title{
Major pollutant changes affected by Covid-19 lockdown in Shanghai
}

Fang Zhang ( $\square$ zhangfang@pric.org.cn )

Polar Research Institute of China https://orcid.org/0000-0002-0300-8273

Yi Han

Durham University

\section{Article}

Keywords: Shanghai, different functional area, major airborne pollutants, Covid-19, effective policy

Posted Date: June 30th, 2021

DOI: https://doi.org/10.21203/rs.3.rs-659194/v1

License: (9) This work is licensed under a Creative Commons Attribution 4.0 International License. Read Full License 


\section{Major pollutant changes affected by Covid-19 lockdown in}

\section{Shanghai}

\section{Fang Zhang (张芳) $)^{1 *}$, Yi han (韩艺) ${ }^{2}$}

1. MNR Key Laboratory for Polar Science, Polar Research Institute of China, Shanghai 200136, China

2. Department of Earth Sciences, Durham University, Durham 27703, United Kingdom

Abstract: China repond quickly to explosure of Covid-19. This paper aims to

evaluate the impact of lockdown on 5 major airborne pollutant in Shanghai.

Chongming, Xuhui and Jinshan areas of Shanghai were studied and compared.

Overall, the Covid-19 lockdown has changed pollutant concentration in both long and short terms. All the five concentrations except for $\mathrm{O}_{3}$ increased. $\mathrm{SO}_{2}$ had significant correlations with all other pollutants. Ozone on eath surface are mainly from green plants and can be reduced by both $\mathrm{NO}_{2}$ and some organic matters. $\mathrm{PM}_{2.5} \mathrm{nd} \mathrm{PM}_{10}$ are more external than local procuced. $\mathrm{NO}_{2}, \mathrm{SO}_{2}$ and $\mathrm{PM}$ matters sharply reduced in Jinshan and Xuhui during dued to the limited usage of fossil fuel. All these activies could both meet humen's neccesary needs and keep a better air quality. Proper and systematic measures should be taken to in keeping better air quality and economic growth in the whole world.

Key Words : Shanghai; different functional area; major airborne pollutants; Covid-19; effective policy 
More than 273.17 million people worldwide have been diagnosed with COVID19 , resulting in more than 3.56 million deaths on $1^{\text {st }} \mathrm{June}^{[1]}$. This has a serious impact on the world economy and health ${ }^{[2]}$. The first infection of Covid-19 was detected in Wuhan in December $2019^{[3]}$ and China responded fast to stop its spread ${ }^{[4]}$ by starting the first-level response in January $2020^{[3]}$. The responces included traffic restrictions and factory closure ${ }^{[5-7]}$. The reported peak cases was on 12 th Feb $^{[8]}$, then the cases gradually decrease to single digits ${ }^{[8]}$.

The Covid-19 also greatly impact air quality due to the lockdown ${ }^{[9,10]}$. The major air pollutants are $\mathrm{NO}_{2}, \mathrm{SO}_{2}, \mathrm{O}_{3}, \mathrm{PM}_{2.5}$ and $\mathrm{PM}_{10}$ in Shanghai ${ }^{[11]}$. During them, $\mathrm{NO}_{2}$ produces photochemical smog and is oxidized by $\mathrm{O}_{3}$ or $\mathrm{O}_{2}$ to produce $\mathrm{NO}_{3}$. This causes photochemical smog and acid rain ${ }^{[12-14]}$. Both traffic and heavy industry produce $\mathrm{SO}_{2}{ }^{[14-16]}$, short-term exposure of which can increase death rate ${ }^{[18]}$. Surface $\mathrm{O}_{3}$ usually forms in agricultural and forestry areas around large cities ${ }^{[13,14,16,19,21]}$. Its concentration varies with season and meteorology ${ }^{[13,21,22,24]}$. High concertation damages human health and agriculture production ${ }^{[7,13,22-24]}$ because $\mathrm{O}_{3}$ oxides nitrogen and VOCs ${ }^{[13,16,17,21,26,27]}$. Both $\mathrm{PM}_{2.5}$ and $\mathrm{PM}_{10}$ are huarmful to humuman health as some toxic gases and pathogenic microorganisms such as bacteria and virus can attached to them ${ }^{[12,15,17-20,22-28]}$. Besides, $\mathrm{PM}_{2.5}$ directly cause human death. It has caused more than 2.1 million people's death because of its acidity penetrating the lower airways which links to the respiratory and cardiovascular disease ${ }^{[12,22,27-30]}$. Short term exposure of these polutants will increase the risk of Covid-19 infection $^{[12,18]}$. Daily average concentrations of the five pollutants were collected from 
$1^{\text {st }}$ January to $9^{\text {th }}$ February, $2020^{[10]}$. Data of the same pollutant belonging to different functional areas were compared to make a comprehensive study. Besides, the corresponding average data from years 2018 and 2019 were used as a baseline to make a comparison.

\section{Results}

Major pollutants in different areas of Shanghai during Covid-19 in year 2020.

Althouth concentrations of different pollutants had diffferernt maximum and minimum values at differernt parts in Shanghai, their changing trends were generally the same (Fig. 1). Four of the five pollutants had decreasing contrations while $\mathrm{O}_{3}$ had increasing concentrations, which showed maximum value at Chongming with large part of green plants, followed by Xuhui with high population density and Jinshan with heavy industry. This was in line with the oxidation effect of $\mathrm{O}_{3}$ to VOCs and $\mathrm{NO}_{\mathrm{x}}{ }^{[10,21,26]}$. So, very significant negtive correlations $(p<0.001)$ were shown between $\mathrm{NO}_{2}$ and $\mathrm{O}_{3}$ (Fig. 2). $\mathrm{NO}_{2}$ decreased immediately after the lockdown as this mainly produced by cars with maximum values in Xuhui, where has the most population density and cars. Correlations between $\mathrm{PM}$ and $\mathrm{O}_{3}$ were also negtive because some VOCs and $\mathrm{NO}_{\mathrm{x}}$ attached to $\mathrm{PM}^{[21,26,27]}$. Due to Spring Festival celebrating by familly barbecues, little peeks appeared after about seven days during the late time of the Chinese Spring Festival (Fig. 1). The celebration increased $\mathrm{NO}_{\mathrm{x}}$ and VOCs, which increased the concentration of $\mathrm{O}_{3}{ }^{[5,21,26,27]}$. The siginificant $(p<0.05)$ positive correlation between $\mathrm{PM}_{2.5}$ and $\mathrm{O}_{3}$ before lockdown shows that increase of $\mathrm{PM}_{2.5}$ attaching with $\mathrm{NO}_{\mathrm{x}}$ and VOCs also increased the concentration of $\mathrm{O}_{3}$. 
Comparison of major pollutants in different functional areas. In Chongming (Fig.

1), the concentration of both $\mathrm{NO}_{2}$ and $\mathrm{SO}_{2}$ decreased by $51 \%$, which was less than half of their original level during the block period. Comparatively, the concentration of $\mathrm{PM}_{2.5}$ only decreased $20 \%$ of concentration before the blockade. The average concentration of $\mathrm{O}_{3}$ almost kept smoothly with values of 79.4 and $79.1 \mu \mathrm{g} / \mathrm{m}^{3}$, respectively, before and after the lockdown period. In Xuhui, the concentration of $\mathrm{NO}_{2}$ and $\mathrm{SO}_{2}$ decreased by $24 \%$ and $28 \%$, respectively; and of $\mathrm{PM}_{10}$ and $\mathrm{PM}_{2.5}$ decreased by $28 \%$ and $14 \%$, respectively. However, concentration of $\mathrm{O}_{3}$ increased $9 \%$ of that in the blockade period. Comparatively, the concentration of $\mathrm{PM}_{2.5}$ only decreased $20 \%$ of concentration before the blockade. In Jinshan, $\mathrm{NO}_{2}, \mathrm{SO}_{2}$ and $\mathrm{PM}_{10}$ relatively decreased by $29 \%, 37 \%$ and $39 \%$ compared with those before the lockdown period. This is in accordance with that this area has the most factories. Like Xuhui, concentration of $\mathrm{O}_{3}$ also increased.

No significant effects on both $\mathrm{PM}_{2.5}$ and $\mathrm{O}_{3}$ were shown by the blockade in all the three parts of Shanghai (Fig. 1). Whereas, very significant effects $(p<0.001)$ on $\mathrm{NO}_{2}$ and $\mathrm{SO}_{2}$ were shown. Weak $(p<0.05)$, significant $(p<0.01)$ and very significant $(p<$ 0.001) effects were respectively shown on $\mathrm{PM}_{10}$ in Chongming, Xuhui and Jinshan parts. This is in line with the control of the two main resouces of $\mathrm{PM}_{10}$, i.e., fossil combustions and vehicle traffics. Significant decrease of both $\mathrm{NO}_{2}$ and $\mathrm{SO}_{2}$ and other reductants reduced the decrease of $\mathrm{O}_{3}$ in both Xuhui and Jinshan. However, the results of $\mathrm{PM}_{2.5}$ was intresting that although the concentration was also obviously decreased, no significant changes were found before and during the lockdown period in different 
functional parts of Shanghai. This indicates that local combustion of fossil fuels may

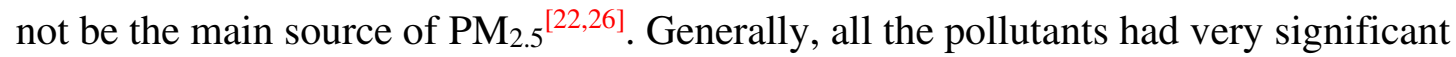
$(p<0.001)$ changes before and during the lockdown period. Only $\mathrm{O}_{3}$ increased more than $20 \%$ than that before the lockdow. Comparatively, concentration of $\mathrm{SO}_{2}$ decreased to $27 \%$, and those of $\mathrm{NO}_{2}, \mathrm{PM}_{2.5}$ and $\mathrm{PM}_{10}$, respectively, decreased to $36 \%$, $72 \%$ and $34 \%$. This effect could last if proper plocies were carried out as shown by the gradually decreasing AIQ before, during and after the lockdown periods, with their respective values of 85.7, 62.8 and 53.5. Most pollutants were clearly separated before and during the lockdown period (Fig. 1 in Supplimentary materials); the same pollutants may have different sources in different functional areas (Fig. 2 in Supplimentary materials).

\section{Comparison of major pollutants in the same days from different years. All}

pollutants varied dramatically in 2020 compared with the same period in 2018 and 2019, especially during the Covid-19 lockdown period (Fig.3). The average decreasing rate of $\mathrm{SO}_{2}, \mathrm{NO}_{2}, \mathrm{PM}_{10}, \mathrm{PM}_{2.5}$ and $\mathrm{O}_{3}$ were $46 \%, 10 \%, 32 \%, 34 \%$ and $3 \%$, respectively, before the lockdown period. Whereas, the corresponding data were $46 \%$, $54 \%, 38 \%, 34 \%$ and $-16.2 \%$, respectively, during the lockdown period. So, the lockdown policy indeed altered the pollutant concentrations. Reducing heavy industry and motor vehicles are effective ways to control most pollutants.

\section{Discussion}

Exposure to air pollution may play important role in COVID-19 incidence and deaths ${ }^{[1,4,13,23,24]}$. Especially $\mathrm{NO}_{2}$ and $\mathrm{PM}_{2.5}$, released from tailpipe ${ }^{[32]}$, is able to 
increase the risk of lung infections ${ }^{[12,15,30,31]}$. During the 5 major pollutants in Shanghai, $\mathrm{NO}_{2}$ and $\mathrm{SO}_{2}$ are environmental indicators directly related to local economic activities ${ }^{[10]}$. More sustainable industry should be established for desulphurisation and to maintain $\mathrm{SO}_{2}$ at a low concentration ${ }^{[10,14]} \cdot \mathrm{NO}_{2}$ concentration was serious to pollution level in Shanghai ${ }^{[6]}$. When GDP in Shanghai reached $38,155.32$ billion yuan in 2019 (China Statistics Bureau, 2019), $\mathrm{NO}_{2}$ became the only major pollutant that failed to meet the nation standard (GB3095-2012). Besides its role in causing lung disease, $\mathrm{NO}_{2}$ might be an important trigger of mental disorders ${ }^{[33}$, ${ }^{34]}$ and associated with morbidity and mortality of COVID-19 ${ }^{[35]}$. Lockdown in 2020 sharply decreased concentration of $\mathrm{NO}_{2}$ by about $45 \%$ compared with the relative value before that period. The whole data were about $28 \%$ and $46 \%$, respectively, lower than the relative decreasing rates in Delhi and Mumbai ${ }^{[5]}$; and about 20\% lower in Almaty while ${ }^{[35,36]}$. The globle decreasing rate were about $9 \%$ and $10 \%$ respectively, in March and April 2020 $0^{[5]}$. This was much higher than the decreasing rate during the lockdown peiod in Shanghai, but almost the same with that before the lockdown, i.e, from $1^{\text {st }}$ to $23^{\text {rd }}$ Jannuary 2020 (Fig.2). Consequently, Shanhai performed well in controlling $\mathrm{SO}_{2}$ compared with other cities in the world. Comparatively, the decreasing rate of $\mathrm{SO}_{2}$ varied little before and during the lockdown periods in this study, but about $10 \%$ higher than those released by traffic in $2020^{[5]}$. Comparatively, the decreasing rate were $27 \%$ and $9 \%$ higher than those in in Delhi and Mumbai. Consequently, $\mathrm{SO}_{2}$ were mainly from heavy industry and traffic, both of which use fossil as fuel. $\mathrm{SO}_{2}$ was the most decreased major pollutant in year 
2020 compared with those from 2018 and 2019. This is different from those of Lima, Madrid, Moscow, Rome, Sao Paulo and Wuhan, where $\mathrm{SO}_{2}$ concentration remained unchanged during lockdown, because power plants and traffic were still operational $^{[36,37]}$.

Driven by particular meteorological conditions, PM are primary pollutant during winter in Shanghai (Shanghai Municipal Bureau of Ecology and Environment, 2020). The wind which contains pollutants came across the Yangzi Delta from November onwards seasonally ${ }^{[5]}$. The concentration of $\mathrm{PM}_{2.5}$ and $\mathrm{PM}_{10}$ result in more dust pollution ${ }^{[38,39]}$. The average concentrations of these two matters were dropped by $66 \%$ and $65 \%$ during past 5 years with proper control of gas emissions from factories in Shanghai and nearby (Shanghai Municipal Bureau of Ecology and Environment, 2020). The decrease of $\mathrm{PM}_{2.5}$ during the lockdown period was more than 4 times of the average all over China (72\%:17\%) ${ }^{[40]}$. The decrease were about $10 \%$ lower than the values caused by traffic in the same periods in Shanghai $(20 \sim 40 \%: 24-47 \%)^{[5]}$, but still more than $10 \%$ higher than the coresponding values in Delhi and Mumbai of Indian ${ }^{[5]}$. So, like $\mathrm{SO}_{2}$, emission of $\mathrm{PM}_{2.5}$ is also well controlled in Shanghai compared with other international cities. There were almost no difference between the concentrations from year of 2018-2019 and 2020 in Shanghai with decreasing rate of $34 \%$. This is comaparable with those in northern China $(29 \pm 22 \%)^{[41]}$ and further validates that large amount of $\mathrm{PM}_{2.5}$ in Shanghai is from the northern region ${ }^{[5,22,26,32]}$.

Ozone is another major pollutant in Shanghai (Shanghai Municipal Bureau of Ecology and Environment, 2020). It also varies with season and meteorology ${ }^{[5,13,16]}$. 
The peak of its concentration occurred in summer due to higher temperature and more sunshine ${ }^{[5]}$. Although concentration of $\mathrm{O}_{3}$ has been recognised by municipal government in Shanghai in 2016, the complexity in $\mathrm{O}_{3}$ forming made it hard to regulate its emission ${ }^{[5,42]}$. In 2016 , concentration of $\mathrm{O}_{3}$ accounted for $57.8 \%$ of primary pollutants in summer and was not improved in following years ${ }^{[10]}$. However, $\mathrm{O}_{3}$ increased much in 2020 with an opposite changing trend of $\mathrm{NO}_{2}$ because of the complex oxidiation effect of $\mathrm{O}_{3}$ to $\mathrm{NOx}^{[5,26,41,42]}$. The average increasing rate $(7 \%)$ of $\mathrm{O}_{3}$ in our study were in accordance with that at the non-road side sites ${ }^{[5]}$. As our data were all from non-road side sites, $\mathrm{O}_{3}$ increased before the lockdowan period exept for that in Chongming with large parts of green plants. This validated the decrease of $\mathrm{NO}_{2}$ $(p<0.001)$ and VOCs could increase $\mathrm{O}_{3}{ }^{[41]}$ and also indicates a banlance has reached in Chongming. Concentration (16\%) during the lockdown period were comparible with those at the roadside sites $(17 \%)$ in Shanghai ${ }^{[5]}$; and increased more than 2.5 times than those in northern China ${ }^{[41,43]}$. All the five major pollutants and the AIQ varied much more than the averages all over China ${ }^{[44]}$.

\section{Major pollutants in different functional areas duiring Covid-19. To our}

knowledge, most work only analyzed the effect of lockdown on some of the airborne pollutant. There are almost no studies to trace pollutant changes in long time series and comparing data between pre-lockdown and post-lockdown ${ }^{[2,9,35,45]}$. They relate empirical evidences to their observed major pollutants and get results of temporary reductions of these pollutions during the lockdown period ${ }^{[2,9,35]}$. Although most part of the world still suffers from Covid-19 and its varietas with more than 27 million 
confirmed cases on 4 th June $2021^{[1]}$, few comprehensive analysis are caried out from pre- to post lockdown's impact on pollutions ${ }^{[4,5]}$. As the first reported Covid-19 cases were in China, which really does well in contralling the virus, it offered an excellent oppotunity to study the air-quality before, during and after the lockdown ${ }^{[6,46]}$.

Concentrations of these pollutants were signifcantly correlated with wether conditions ${ }^{[46,47]}$. The average temperature was about 8 to $9^{\circ} \mathrm{C}$ with relatively high pressure in Shanghai in January. This aggravated air pollution (Meteorological Administration Official Website). Furthermore, sand from Mongolia desert was carried to Shanghai in winter. This increased the pollution of $\mathrm{PM}_{10}$ in the air ${ }^{[10]}$. If the sand dust superposed the impact of local high pressure, it would spread further from north to south Yangzi Delta area including Shanghai to increase the concentration of $\mathrm{PM}_{2.5}$ there ${ }^{[5,25,47,48]}$. Rainfall and wind speed also matter ${ }^{[5,48]}$. The average precipitation is 116.06 mmand $69.25 \mathrm{~mm}$ in in January and February, rspectively ${ }^{[7]}$. This indicates there was enough rain over the lockdown period. Rain also absorbs the pollutant and lower down the pollutant concentration ${ }^{[16,22,29]}$. The average wind speed was $3.75 \mathrm{~m} / \mathrm{s}$, a low speed for the spread of airborne pollutants in Shanghai ${ }^{[10]}$. So, although there were enough rainfall, the low wind speed and high pressure still increased airborne pollutants.

Availability of lockdown policy respond to diffusion of Covid-19. As we know, Covid-19 brings bad effects on not only human health ${ }^{[18,20,29,49]}$, but also socioeconomic $^{[18,29]}$. The lockdown policy indirectly offered chances to study and comparison environmental changes in China before, during and after the lockdown 
time $^{[1]}$. Policies like lockdowning cities and shutdowning factories could reduce the emission of air pollutants from transport and production ${ }^{[3,16,18,23]}$. Xuhui, Chongming and Jinshan with various natural landscapes and anthropologic facilities are different functional areas in Shanghai. Compared pollutant changes in the three areas can well discuss how the pollutant concentration was affected by lockdown itself and other determinants $^{[3,16,23,29]}$. As mentioned earlier, the lockdown included both the restriction on nonessential travel and the interruption of manufacturing $\operatorname{activities}^{[3,26,47]}$. Given that the relatively shorter lockdown in Shanghai during the Spring Festival, i.e., $24^{\text {th }}$ Jan to $9^{\text {th }}$ Feb did not involve much industrial production, Table 1 only shows the traffic control in Shanghai as background applicable to all 3 sites. The results is in accordance with the ones in Fig. 1, i.e, only 2 or 3 little peeks were found for $\mathrm{SO}_{2}, \mathrm{NO}_{2}$ and $\mathrm{PM}_{10}$, the main resouce of which are fuel combustion $[9,25,38]$. The general decrease during this period is in accordance with the "holiday effect" ${ }^{, 50]}$. The little pollutant concentration peaks were mainly from cooking and traffic. Whereas, low concentrantions were found to both $\mathrm{O}_{3}$ and $\mathrm{PM}_{2.5}$ As mentioned above (Fig. 2 and Fig. 3), $\mathrm{O}_{3}$ reduced because of increase of $\mathrm{NO}_{2}$ and organic reduction pruduced by human activities ${ }^{[42,50]}$. The decreasing rate before lockdown (3\%) was almost the same with the value during the lockdown period in northern China ${ }^{[41]}$. Whereas the source of $\mathrm{PM}_{2.5}$ is external and has less correlation with the local human activities in Shanghai ${ }^{[25]}$. Only $\mathrm{SO}_{2}$ has significant correlations with all other pollutants, that is because it is mainly from fuel combustion, and can attach to $\mathrm{PM}_{2.5}$ and $\mathrm{PM}_{10}{ }^{[22]}$. 
The globle air quality had a dramatic promotion throughout the pandemic of COVID-19 $9^{[44,46]}$ because the lockdown supplied a relatively non-industrial period $^{[36,40,41,44-47,50]}$. Isolation is an effective way to block the spread of COVID-19 $[36,40,41,44-47,50]$. However, this means that people have to be blocked at home or somewhere else. They are unable to go out for work, and plants have to stop or reduce their production. This results in lack of living material in some place and could increase human's mental problems such as anxiety and depression ${ }^{[20,49]}$, which would increase the instability of society ${ }^{[20]}$. The progress of social economy is largely dependent on development of some heavy industries, which discharge greenhouse gas and accelerate global warming ${ }^{[2]}$.

Implication on Environment Policies taken by China. The lockdown peirod in China during the COVID-19 just rightly provided an effective model that could be pushed throughout the whole world. Concentration of $\mathrm{NO}_{2}$ in oceans was 3 to 4 times lower than those in total land without the Antarctic ${ }^{[41]}$, where has a huge ozone hole and with low $\mathrm{NO}_{2}$ concentration ${ }^{[51]}$. The data of Shanghai highlights efforts of keeping pollutant concentration low for years when its growth trajectory takes sustainability into account ${ }^{[17,22]}$. Although the improvement of air quality is good within the lockdown period, it is unlikely to be maintained for long if the economy is still supposed to grow at a high speed. Necessary policies should be made to maintain or even improve the post-lockdown air quality ${ }^{[45]}$. Wiser policies rather than forced reducing industry and transport should be taken into consideration ${ }^{[23]}$. Green energy sources such as wind, solar and photovoltaic power generation are good alternatives 
to traditional fossil consumptions, which is high in pollution. Besides, China respond to the concept and task of "carbon neutralization" and "carbon peak" at the first time in order to better safeguard the world's environment and stabilize the climate. Besides, people in China quickly and positively respond to the Blue Carbon Initiative. The plan's aim is to ensure economic growth on the basis of recover good natural environment. It is a good way to control carbon releasing to the atmosphere as ocean is a big sink to the greenhouse gases, such $\mathrm{CO}, \mathrm{CO}_{2}$ and $\mathrm{CH}_{4}{ }^{[52-54]}$.

\section{Methods}

Data collection. The daily data of the polutants $\left(\mathrm{NO}_{2}, \mathrm{SO}_{2}, \mathrm{O}_{3}, \mathrm{PM}_{2.5}\right.$ and $\left.\mathrm{PM}_{10}\right)$ were provided by Shanghai Municipal Bureau of Ecology and Environment (https://sthj.sh.gov.cn/), and average values were used for each day. Three parts (Fig. 4), i.e., Chongming, Xuhui and Jingshan stations were chosen as different functional parts for data analysis. Chongming represents the area covered by large amounts of vegetation. Its total area is $50.94 \mathrm{~km}^{2}$ and population of 678,000 with density of about 1 person $\mathrm{km}^{-2}$ by the end of 2018. Xuhui is the Central Business District (CBD) area for Shanghai. Its total area is $1413 \mathrm{~km}^{2}$ and had 818,100 permanent residents ${ }^{[10]}$ with density of about 13,310 person $\mathrm{km}^{-2}$ by the end of 2018 . Xuhui is the typical area to study how concentrations of the major air pollutants vary in populated urban environment. There are 176 companies registered in Jinshan industrial zone and most of them are chemical companies. In addition, 59 of those firms exhale pollutants ${ }^{[10]}$. Its total area is $50.94 \mathrm{~km}^{2}$ and the registered population were 522,300 with density of about 10,253 person $\mathrm{km}^{-2}$ by the end of 2020 . We colected a enviromental data set 
containing 613 values belonging to year of 2018-2020 from all the three stations.

Data Processing. 1. Two comparisons were done: First, comparison before lockdown period (1st Jan-23rd Jan) and during lockdown period (24th Jan - 9th Feb) in year of 2020. Second, comparison data from the same dates but of different years (average data of 2018-2019 and data of 2020).

2. One-way ANOVA, Nonmetric Multidimensional scaling (NMDS) analysis and cluster analysis were used to process the data. SPSS (SPSS Inc., Chicago, USA) was used to do one-way ANOVA; whereas R were used to do cluster analysis (version 3.4.1).

3. The calculation of the Air Quality Sub-Index (AQI) for Air Pollutant (IAQIP) measures the total quality of air are as followed:

$A Q I=\max \left(I_{1}, I_{2}, \ldots, L_{n}\right) ; I A Q I_{P}=\frac{I_{\text {high }}-I_{\text {low }}}{C_{\text {high }}-C_{\text {low }}}\left(C_{P}-C_{\text {low }}\right)+I_{\text {low }}$

$C_{P}$ : the concentration of pollutant $p ; C_{\text {low }}$ : the concentration breakpoint that is $\leq C_{P}$ $C_{\text {high }}$ : the concentration breakpoint that is $\geq C_{P} ; I_{\text {low }}$ : the index breakpoint corresponding to $C_{\text {low }} ; I_{\text {high }}$ : the index breakpoint corresponding to $C_{h i g h}$.

\section{Reference}

1. Real-time epidemic tracking analysis of COVID-19. https://www.360kuai.com/mob/subject/400.

2. Wang, Q. \& Su, M.. A preliminary assessment of the impact of COVID-19 on environment - A case study of China. Sci. Total. Environ., 728(1), 138915. https://doi.org/10.1016/j.scitotenv.2020.138915 (2020a). 
3. Xu, Z., Chou, C., Liang, J.Y, Chou, C.K. \& Shiu, C.J. Pathological findings of COVID-19 associated with acute respiratory distress syndrome. Lancet Respir. Med. 8(4), 420-422. 10.1016/S2213-2600(20)30076-X (2020) .

4. Haug, N., Geyrhofer, L., Londei, A.D., Larrive, A., Loreto, V. \& Pinior, B.. Ranking the effectiveness of worldwide COVID-19 government interventions. Nature Human Behaviour. 4, 1303-1312(2020).

5. Wu, C., Wang, H. Cai, W, He, H., Ni, A.\& Peng, Z. Impact of the COVID-19 lockdown on roadside traffic-related air pollution in Shanghai, China, Build and Environ., 194, 107718. https://doi.org/10.1016/j.buildenv.2021.107718 (2021).

6. Wang, Y., Yuan, Y. Wang, Q., Liu, C. \& Cao, J.. Changes in air quality related to the control of coronavirus in China: Implications for traffic and industrial emissions. Sci. Total Environ. 731, 139133. https://doi.org/10.1016/j.scitotenv.2020 (2020b).

7. Shanghai implements "the strictest scientific prevention and control measures" after launching a first-level response mechanism. https://tech.sina.com.cn/roll/2020-01-25/doc-iihnzhha4640599.shtml.

8. Chinese Centre for Disease Control and Prevention. http://www.chinacdc.cn/en/ 2020.

9. Wyche, K.P., Nichols, M., Parfittc, P., Gregga, D.J., Smallbonea, K.L. \& Monksd, P.S. Changes in ambient air quality and atmospheric composition and reactivity in the South East of the UK as a result of the COVID-19 lockdown. Sci. Total Environ. 755(1), 142526. https://doi.org/10.1016/j.scitotenv.2020.142526 (2021). 
10. Shanghai Municipal Bureau of Ecology and Environment. Joint Operation of Accelerating the Measures of Air Pollution Containment. https://sthj.sh.gov.cn/.2021

11. Wu, J.T., Leung K.L.\& Leung, M. Nowcasting and forecasting the potential domestic and international spread of the 2019-CoV outbreak originating in Wuhan, China: a modelling study. Lancet, 395, 689-697 (2020). https://doi.org/10.1016/ S0140-6736(20)30260-9.

12. $\mathrm{PM}_{2.5}$ and $\mathrm{PM}_{10}$, you may hear a lot! What are they actually? https://www.sohu.com/a/290591956_120029446.

13. Sicard, P., Marco, A., Agthokleous, E., Feng, Z.Z, Xu, X. \& Paoletti, E. Amplified ozone pollution in cities during the COVID-19 lockdown. Sci. Total Environ. 735, 139542 (2020).

14. Su, S. Sulphur dioxide emissions from combustion in china: from 1990. https://doi.org/10.1016/j.amsu. 102339 (2021).

15. Wang L., Zhao X., Xu W, Tang J. \& Jiang X. Correlation analysis of lung cancer and urban spatial factor: based Correlation analysis of lung cancer and urban spatial factor: based on survey in Shanghai. J. Thoracic Disease, 8(9), 9373. (2016).

16. Wang, T., Xue, L., Brimble, P., Li, Y.l. \& Zhang, L. Ozone pollution in China: A review of concentrations, meteorological influences, chemical precursors, and effects. Sci. Total Environ. 575, 1583-1596 (2017).

17. Nam, K.M., Zhang, X., Zhong, M., Saikawa, E.\& Zhan, X. Health effects of ozone 
and particulate matter pollution in China: a province-level CGE analysis. Ann. Reg. Sci. 63, 269-293. https://doi.org/10.1007/s00168-019-00924-z (2019).

18. Xie, J., Teng J., Fan Y., Xie R. \& Shen A. The short-term effects of air pollutants on hospitalizations for respiratory disease in Hefei. China. Int. J. Biometeorol. 63: $315-$ $326(2019)$.

19. Chuang K.J., Yan, H.Y, Chiu, S.Y. \& Cheng T.J. Long-term air pollution exposure and risk factors for cardiovascular diseases among the elderly in Taiwan. Occup. Environ., 68, 64-68 (2011).

20. Seo, J.H., Kim, S.J. Lee, M. \& Kang J.I. Impact of the COVID-19 pandemic on mental health service use among psychiatric outpatients in a tertiary hospital. $J$. Affect. Disorders. 290, 279-283. https://doi.org/10.1016/j.jad.2021.04.070 (2021).

21. Sillman, S. The relation between ozone, NOx and hydrocarbons in urban and polluted rural environments. Atmos. Environ. 33, 1821-1845 (1999).

22. Chen, Z., Cai, J., Gao, B., He, B. \& Xie X. Detecting the causality influence of individual meteorological factors on local PM2.5 concentration in the Jing-Jin-Ji region. Scientific Reports, 7, 40735 (2017).

23. Zhang, J. Transport policymaking that accounts for COVID-19 and future public health threats: A PASS approach. Transport Policy, 99, 405-418. https://doi.org/10.1016/j.tranpol.2020.09.009. 2020.

24. Zhu, W.H. Port-Related Emissions, Environmental Impacts and Their Implication on Green Traffic Policy in Shanghai. Sustainability, 12, 4162. https://doi.org/10.3390/su12104162 (2020). 
25. An, X., Hou, Q.N. \& Zhai, S. Assessment of human exposure level to $\mathrm{PM}_{10}$ in China. Atmospheric Environment. 70, 376-386 (2013).

26. Ma, J., Chen, Z., Wu, M., Feng, J. Horii Y., Ohura T., \& K. Kannan. Airborne $\mathrm{PM}_{2.5} / \mathrm{PM}_{10}$-Associated Chlorinated Polycyclic Aromatic Hydrocarbons and their Parent Compounds in a Suburban Area in Shanghai, China. Environ. Sci. Tech. 47 (14), 7615-7623 (2013).

27. Zeng, P., Lyu, X.P., Guo, H., Cheng, H.R, Jiang, F., Pan, W.Z, Wang, Z.W. \& Liang, S.W. Causes of ozone pollution in summer in Wuhan, Central China. Environ. Pollut. 241, 852-861(2018).

28. Becker, S. \& Soukup J.M.. Exposure to urban air particulates alters the macrophage mediated inflammatory response to respiratory viral infection. $J$. Toxic.. Environ. Health I 57, 445-457 (1999).

29. Cai, Q., Lu, J., Boons, Q., Xu, Q.F., Guo, Q., Sun, Q.W. \& Zhao, H.Y. Influence of meteorological factors and air pollution on the outbreak of severe acute respiratory syndrome. Public Health, 121, 258-265 (2007).

30. Horne, B.D, Joy, E.A., Hofmann, M., Gesteland, H., Cannon, J.B., Lefler, J.S. \& Blagev, D. Short-term elevation of fine particulate matter air pollution and acute lower respiratory infection. Am. J. Respir. Crit. Care Med. 198, 759-766 (2018).

31. Wang L., Zhao X., Xu W., Tang J. \& Jiang X. Correlation analysis of lung cancer and urban spatial factor: based on survey in Shanghai. J. Thoracic Disease, 8 (9): 2626-2637 (2016).

32. Ma, C., Zhuang, T., Zhang, Z., Wang, J., Yang, F., Qiao C. \& Lu, M. Tailpipe 
emission characteristics of PM2.5 from selected on-road China III and China IV diesel vehicles, Aerosol Sci. Tech. 52(7), 799-808, DOI: 10.1080/02786826.2018.1466027(2018).

33. Qiu, H., Yu, H., Wang, L., Zhu, X., Chen, M., Zhou, L., Deng, R., Zhang, Y. Pu, X. \& Pan J. The burden of overall and cause-specific respiratory morbidity due to ambient air pollution in Sichuan Basin, China: A multi-city time-series analysis. Environ. Res. 167, 428-436. https://doi.org/10.1016/j.envres.2018.08.011(2018).

34. Guxens, M., Lubczyńska, M.J., Muetzel, R., Dalmau-Bueno, A., Jaddoe, V. \& Hoek, G. Air pollution exposure during fetal life, brain morphology, and cognitive function in school-age children. Biological Psychiatry, S0006322318300647 (2018).

35. Kerimaray, D.R. Behavioral interventions in acute COVID-19 recovery: A new opportunity for integrated care. General Hospital Psychiatry, 69, 113-114. https://doi.org/10.1016/j.genhosppsych.2020.07.001 (2021).

36. Kerimray, A., Baimatova, N. , Ibragimova, O.P., Gao, W., Tie, X., Xu, J., Huang, R., Mao, X., Zhou, G. \& Chang, L. Assessing air quality changes in large cities during COVID-19 lockdowns: The impacts of traffic-free urban conditions in Almaty, Kazakhstan. SCI. Total Environ. 730:139179. https://doi.org/10.1016/j.scitotenv.2017.06.099 (2020).

37. Ma, S. Yao, J. Gao, L. Ma, X .\& Zhao, Y. Experimental study on removals of SO2 and NOX using adsorption of activated carbon/ microwave desorption, J. Air Waste Manag. Associ. 62, 1012-1021. DOI: 10.1080/10962247.2012.695320 
(2012).

38. Qin, Y. Weekend/weekday differences of ozone, NOx, CO, VOCS, PM10 and the light scatter during ozone season in southern California. Atmos. Environ. 38, 3069-3087. (2004)

39. Richmond-Bryant, J., Saganich, C., Bukiewicz, L. \& Kalin, R. Associations of PM2.5 and black carbon concentrations with traffic, idling, background pollution, and meteorology during school dismissals. Sci. Total Environ. 407, 3357-3364. (2009).

40. He, G., Pan, Y. \& Tanaka, T.. The short-term impacts of COVID-19 lockdown on urban air pollution in China. Nat. Sustain. 3, 1005-1011. https://doi.org/10.1038/s41893-020-0581-y (2020).

41. Bray, C.D., Nahas, A., Battye, W.H., Aneja, V.P. 2021. Impact of lockdown during the COVID-19 outbreak on multi-scale air quality. Atmos. Environ., 254, 118386. https://doi.org/10.1016/j.atmosenv.2021.118386.

42. Gao, W., Tie, X., Xu, J., Huang, R., Mao, X., Zhou, G. \& Chang, L. Long-term trend of $\mathrm{O}_{3}$ in a mega City (Shanghai), China: Characteristics, causes, and interactions with precursors, Sci. Total Environ. 603-604, 425-433. https://doi.org/10.1016/j.scitotenv.2017.06.099 (2017).

43. Shi, X. \& Brasseur, G.P.. The Response in Air Quality to the Reduction of Chinese Economic Activities During the COVID-19 Outbreak. Geophy. Res. Lett. 47, e2020GL088070. https://doi.org/10.1029/2020GL088070Received 25 MAR (2020). 
44. He, G., Stratton C.W. \& Tang Y.WThe short-term impacts of COVID-19 lockdown on urban air pollution in China. Nat. Sustain. 3, 1005-1011 (2020)

45. Sharifi, A., Khavarian-Garmsir, R.A. The COVID-19 pandemic: Impacts on cities and major lessons for urban planning, design, and management. Sci. Total Environ. 749, 142391. https://doi.org/10.1016/j.scitotenv.2020.142391 (2020).

46. Chen, Q., Pan, S. Transport-related experiences in China in response to the Coronavirus (COVID-19), 2020. Trans. Res. Inter. Perspec. 8, 100246, https://doi.org/10.1016/j.trip.2020.100246 (2020).

47. Copat, C.,Cristaldi, A., Fiore, M., Grasso, A., Zuccarello, P. \& Signorelli S.S. The role of air pollution (PM and $\left.\mathrm{NO}_{2}\right)$ in COVID-19 spread and lethality: A systematic review. Environ. Res. 191, 110-129 https://doi.org/10.1016/j.envres.2020.110129 (2020).

48. Esworthy, R.. Air quality: EPA's 2013 changes to the particulate matter (PM) standard. Congress. Res. Service 7-5700, 6 (2013).

49. Chen, S., Dai, J, Hu Q. Chen, H., Wang, Y., Gao J., Zheng, P. \& Fu, H. Public anxiety and its influencing factors in the initial outbreak of COVID-19. 2020, Fudan. Univ. J. Med. Sci. 43 (3), 385-391.

50. Tan, P., Chou, C., , Chou, C.-K.C. Impact of urbanization on the air pollution "holiday effect" in Taiwan. Atmos. Environ. 70, 361-375. https://doi.org/10.1016/j.atmosenv.2013.01.008 (2013).

51. Noxon, J.F. Stratospheric $\mathrm{NO}_{2}$ in the Antarctic Winter. Geophy. Res. Lett. 5 (12), 1021-1022 (1978). 
52. Zhan, L.L., Chen, J., Zhang, J.Y., Li, Y. \& Wu, M.. A permanent $\mathrm{N}_{2} \mathrm{O}$ sink in the Nordic Seas and its strength and possible variability over the past four decades, $J$. Geophys. Res. Oceans. 121, 5608-5621. doi:10.1002/2016JC011925 (2016).

53. Altshuler, I., Hamel, J., Turney, S., Magnuson, E., Lévesque, R., Greer, C.W. \& Whyte, L.G. 2019. Species interactions and distinct microbial communities in high Arctic permafrost affected cryosols are associated with the $\mathrm{CH}_{4}$ and $\mathrm{CO}_{2}$ gas fluxes. $3711-3727$.

54. Shakirov, R.B., Mau, S., Mishukova, G.I., Obzhirov, A.I., Shakirova, M.V. \& Mishukova, O.V. The features of methane fluxes in the western and eastern Artcic: A review. Part I. Geos. Trans. Zones, 4(1), 4-25. https://doi.org/10.1111/1462$2920.14715(2020)$. 


\section{Figure legends \& Figures}

Fig. 1 Changes of major pollutants from 1st Jan to 9th Feb with lockdown beginning date of $23^{\text {rd }}$ Jan at different parts of Shanghai
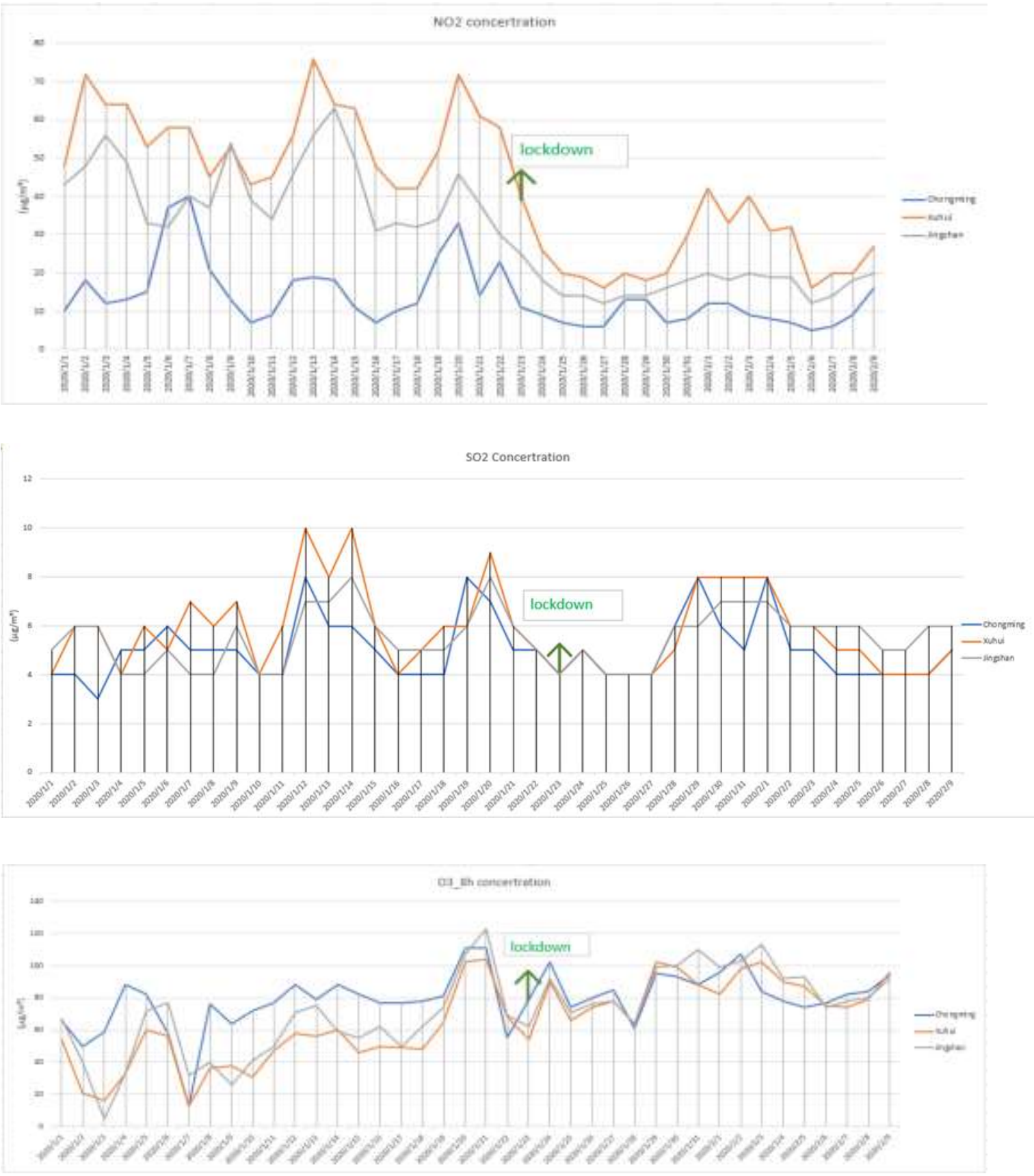

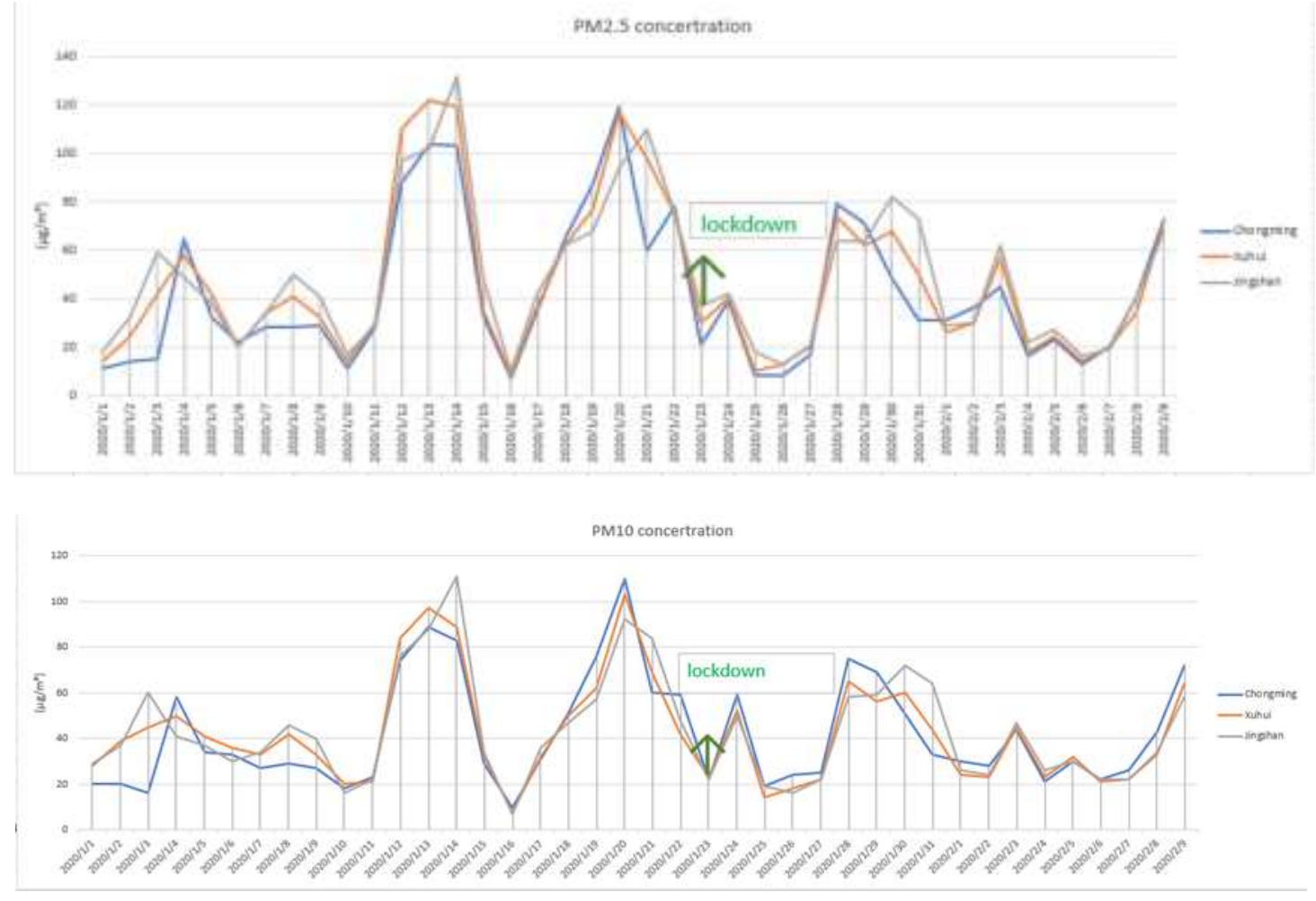
Fig. 2 One-way ANOVA analysis for different parts and total of Shanghai before and during the Covid-19: during (B) and before (F) lockdown peirod
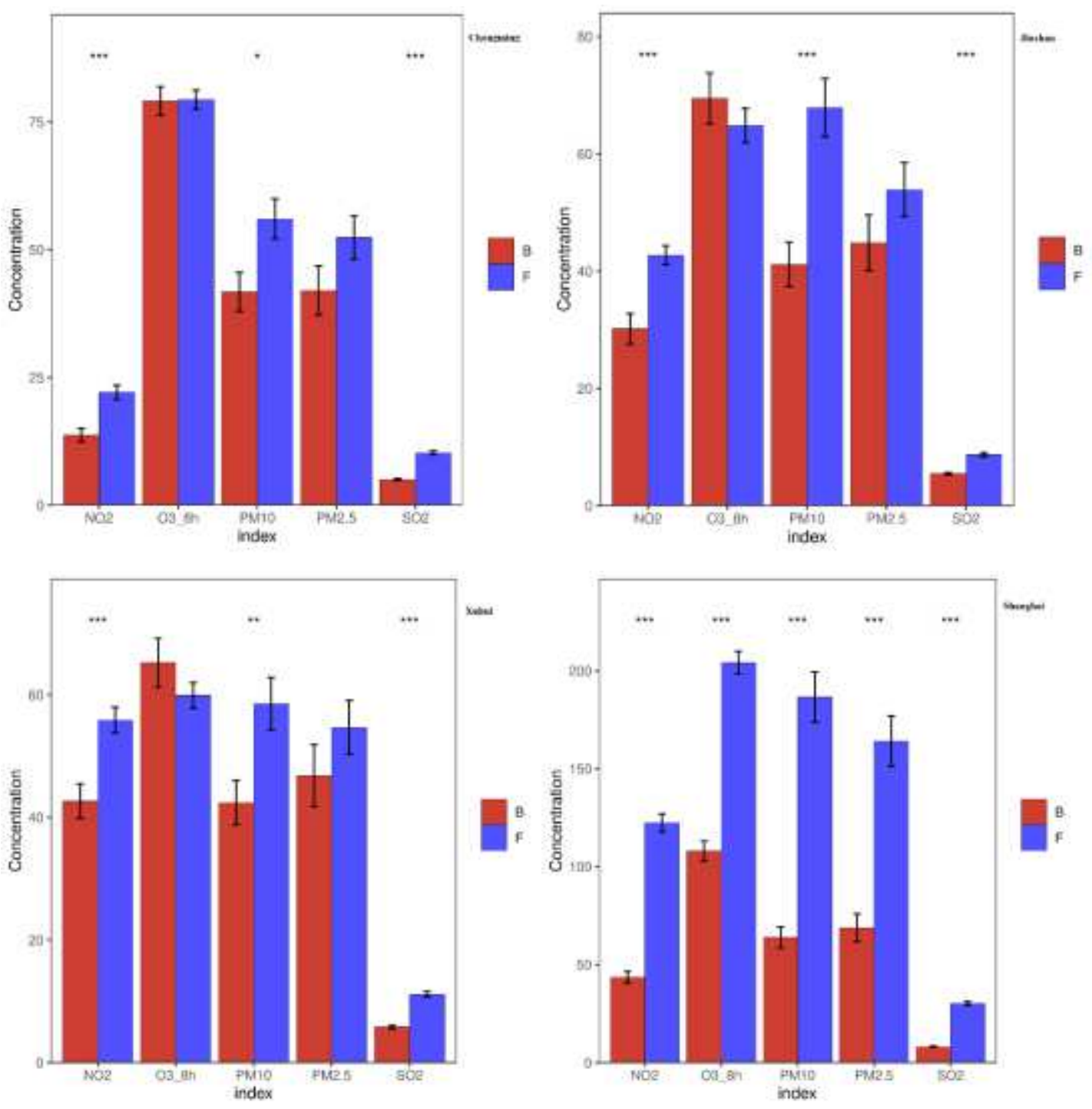
Fig 3. Average concentrations of different pollutants in different years of Shanghai before and during the Covid-19 period
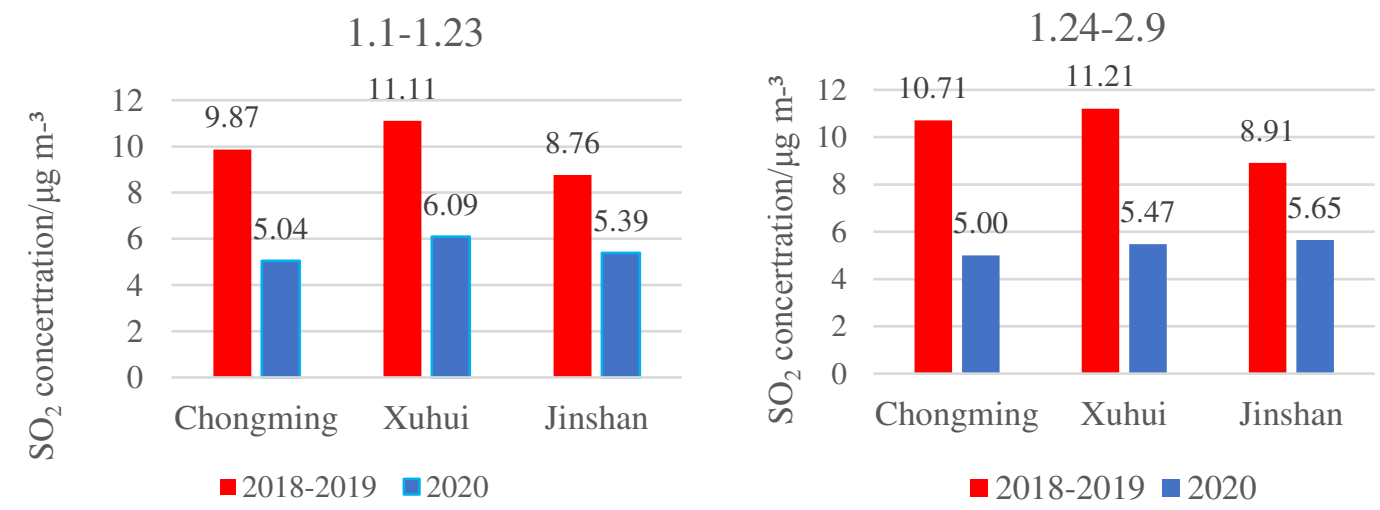

\section{$1.1-1.23$} 58.5955 .52

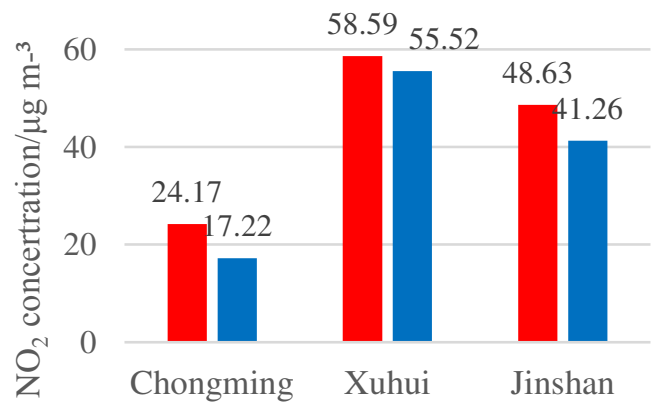

ロ2018-2019 $\mathbf{2 0 2 0}$

$1.24-2.9$

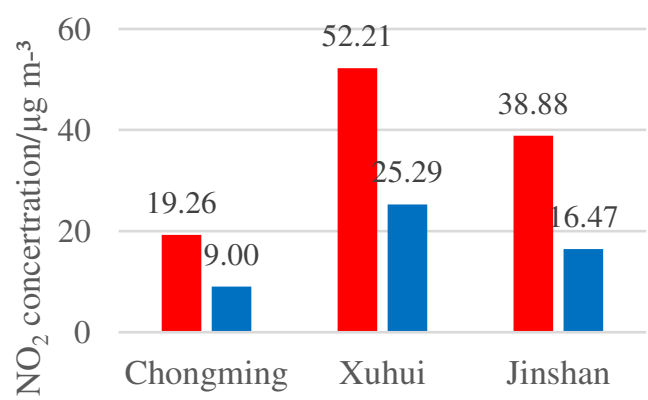

-2018-2019 2020

\section{$1.1-1.23$}

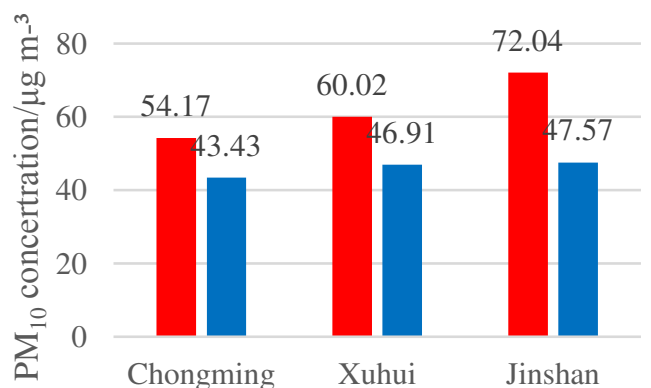

-2018-2019 - 2020

$1.24-2.9$

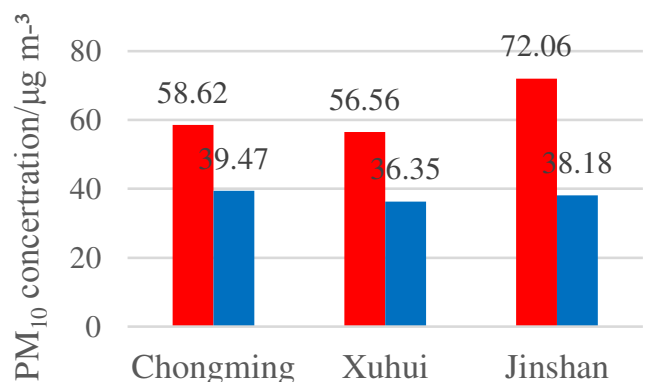

—2018-2019 —2020 

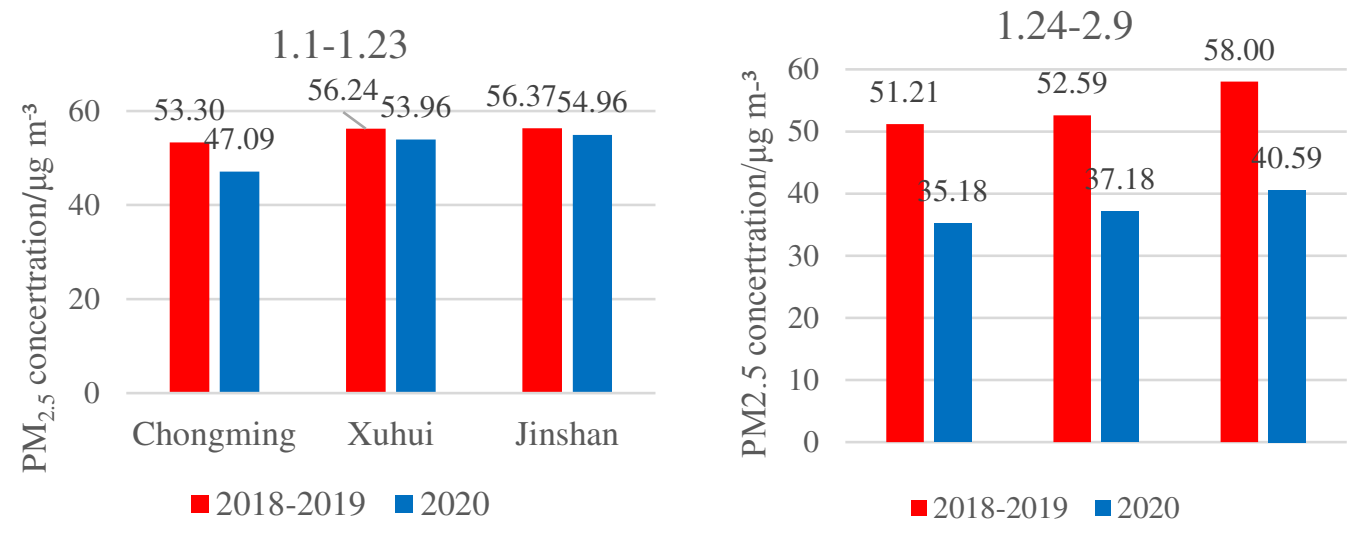

Fig. 4 Sampling areas in Shanghai, China

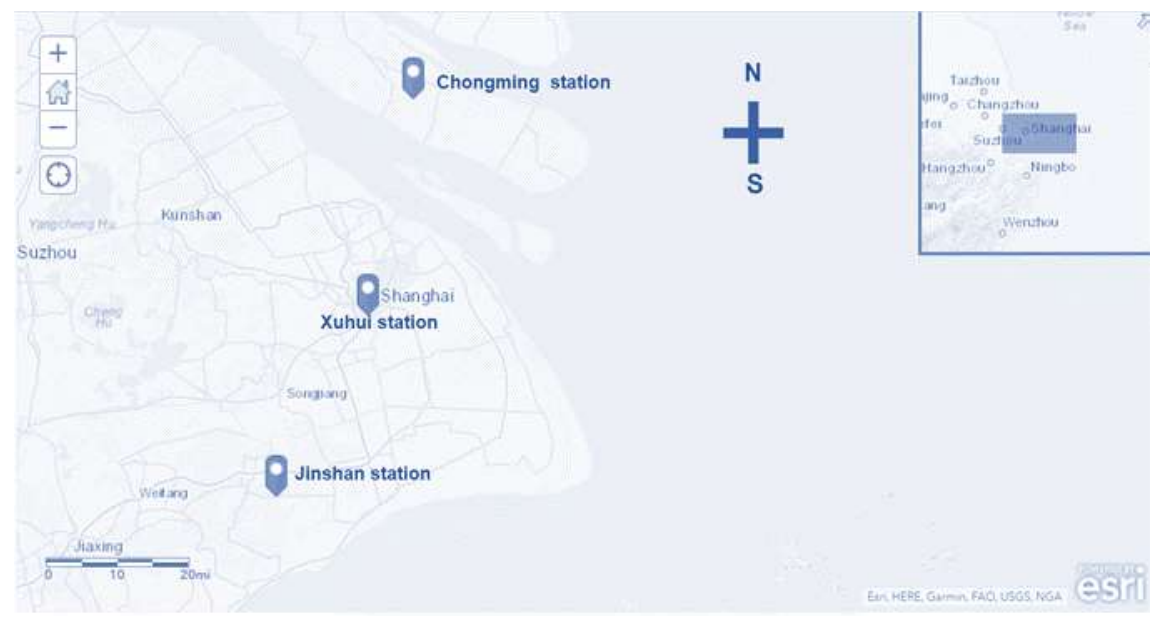


Table 1 Traffic control in January and February of 2020 in Shanghai from Shanghai

Bureau of Statistics

\begin{tabular}{l|lrr}
\hline & January & February & \\
\hline Total amount of cargo & & & \\
transported (10,000 tons) & 10173.28 & 8583.22 & $-8.48 \%$ \\
Highway & 3560 & 2200 & $-23.61 \%$ \\
Airport & 30.22 & 19.16 & $-22.40 \%$ \\
Railway & 1050.49 & 68.25 & $-87.80 \%$ \\
Harbour & 6.3 & 0.01 & $-99.68 \%$ \\
\hline
\end{tabular}




\section{Supplementary Files}

This is a list of supplementary files associated with this preprint. Click to download.

- Supllimentarymaterials.docx

- Supllimentarymaterials.docx 